\title{
Innovative Thinking of Engineering Education with the Industrial Design Method
}

\author{
Jiabei Jiang ${ }^{\text {a, }}$, Ding Zhou ${ }^{\mathrm{a}}$, Yuqing Zou ${ }^{\mathrm{a}}$ \\ ${ }^{a}$ School of Industrial Design at Nanjing University of the Arts, 15 Huju North Rd., Nanjing 210013, P.R. China \\ *jiangjb1015@hotmail.com
}

\begin{abstract}
In recent years, engineering education focuses on cultivating the students' ability of product manufacturing and industrial innovation, while industrial design education offers fantastic thinking and logical method. As a result, many universities have opened the multidisciplinary course of product design engineering. By investigating the settings of the course, it is found that its main idea is innovative design thinking, which is the reflection of the industrial design method. This paper tries to discuss the feasibility of integrating the industrial design method into engineering education, with the purpose of inspiring the design thinking of the students. The authors attended the Summer Program for Innovative Engineering Design (SPIED) for two years, and gained some experience of teaching the engineering students in this program. In this paper, the project and needs of engineering students are analyzed by taking the course in SPIED 2015 as an example. The authors guided the students to find the possible innovative points with industrial design method in the class. Furthermore, a questionnaire survey was conducted for evaluating the teaching effect. According to the survey result, the students showed more interests in the innovative thinking training, and the user research and the course could significantly improve their innovative thinking.
\end{abstract}

Keywords: innovative thinking, engineering education, industrial design method, design thinking

\section{Introduction}

With the development of the manufacturing industry, a higher requirement has now been put forward for the traditional engineering education, and the integration of research with practice has become a large challenge. Most attention in engineering education is still paid on research and product development, and little on the connection with the market. On the other hand, the education of industrial design ${ }^{(1)}$ has a very close connection with manufacturing, and puts the main attention on the research of market and user needs, though it is deficient in terms of the research on technology development. Accordingly, many of the universities have set up the discipline of product design engineering ${ }^{(2)}$, which combines the advantages of the above-mentioned two disciplines. After comparing the course settings in these universities, it is found that "design thinking" ${ }^{(3)}$ is the core idea in these courses ${ }^{(4)-(5)}$. This paper discusses how to apply design thinking in general engineering courses to enable innovative design. An experiment was performed in an international engineering design education program, and a method was presented for helping the engineering students find the possible innovative points during the project process.

This international engineering design education program is a two-week workshop, which involves students from different engineering majors and countries. The purpose of this program is to make innovative design for solving the actual problems in this era or in the future. It was found that most of the students and professors participating in this program came from the engineering field, and focused on "making" rather than "thinking". In fact, the innovation runs through the whole design process of the project, not on some special step. The engineering students usually ignored easily this fact. They don't know why the "thinking" is important and how to think during the design process. Therefore by taking advantage of the exercise chances within the classroom, the authors tried to guide the students to find the possible innovative points with the industrial design method and help them build the design thinking consciousness. 
Table 1. The traditional design method.

\begin{tabular}{|c|c|c|}
\hline Step & Industrial Design Method & Example \\
\hline 1 & Problem & $\begin{array}{l}\text { Riso verde } \\
\text { (Green rice) }\end{array}$ \\
\hline 2 & Problem definition & $\begin{array}{l}\text { Prepare the riso } \\
\text { verde with } \\
\text { spinach for four } \\
\text { persons }\end{array}$ \\
\hline 3 & Factors in the problem & $\begin{array}{l}\text { Rice, spinach, } \\
\text { prosciutto, onion, } \\
\text { oil, salt, pepper, } \\
\text { and broth }\end{array}$ \\
\hline 4 & Date collection & $\begin{array}{c}\text { Did anybody cook } \\
\text { this before? }\end{array}$ \\
\hline 5 & Data analysis & $\begin{array}{l}\text { How did he do? } \\
\text { What can I learn } \\
\text { from him? }\end{array}$ \\
\hline 6 & Creation & $\begin{array}{l}\text { How to combine } \\
\text { the research data } \\
\text { in the right mode? }\end{array}$ \\
\hline 7 & Material and technique & $\begin{array}{l}\text { What kind of } \\
\text { rice/pot shall I } \\
\text { use? What about } \\
\text { the fire? }\end{array}$ \\
\hline 8 & Experimentation & Try and taste \\
\hline 9 & Models & $\begin{array}{c}\text { Decide the best } \\
\text { taste }\end{array}$ \\
\hline 10 & Verification & $\begin{array}{c}\text { Good for four } \\
\text { persons }\end{array}$ \\
\hline 11 & Design and construction & Cooking process \\
\hline 12 & Solution & $\begin{array}{c}\text { Put the riso verde } \\
\text { into hot dishes }\end{array}$ \\
\hline
\end{tabular}

\section{Industrial design and the method for innovation}

\subsection{Industrial design}

The first period of the industrial design started from the middle 19th century, which witnessed the transition from the handicraft industry to the mechanical industry; then in the 20th century, the Bauhaus proposed the principle that form follows function-meaning a problem should be solved in a systemic and logical way-which marked the beginning of the second period of industrial design; and in 1981, with the development of the manufacturing industry, the
International Council of Societies of Industrial Design (ICSID) ${ }^{(6)}$ defined industrial design as a process of design applied to products that are to be manufactured through techniques of mass production.

From the beginning of the 21-century, with the advent of the immaterial era, the disciplines of the industrial design have been further extended. Recently, at the 29th $\operatorname{ICSID}^{(6)}$ General Assembly in Gwangju, South Korea, the Professor Practise Committee re-defined industrial design as follows: "Industrial Design is a strategic problem-solving process that drives innovation, builds business success and leads to a better quality of life through innovative products, systems, services and experiences."

Despite its short history, the industry design field has an important role: it offers the approach to finding problems, thereby enabling problem settlement based on the combination of various resources and innovative thinking. The focus of industrial design is the method and its purpose is to explore the real user needs so as to allow good user experience. The user experience is defined as "a person's perceptions and responses that result from the use or anticipated use of a product, system or service" by the international standard on ergonomics of human system interaction. A good understanding of the users can allow the designer to find the specific innovation points. However, engineering students can hardly identify user needs due to the lack of experience.

\subsection{The method for innovative thinking}

Innovative thinking is a reflection of the design method, which is implemented in the design process. This is the core part of the industrial design innovation. The selection and implementation of the method reflect the innovative thinking mode. Shown in Table 1, as a rational and scientific method, the traditional design $\operatorname{method}^{(7)}$ emphasizes: problem finding and defining, date research and analysis and manufacturing.

In the 20th century, design thinking meant the exploration and integration of design methodology. Design thinking was first defined and advocated by Rolf Faste, a teacher in Stanford University; later, his colleague David M Kelley used it in commercial activities in the 80 s and 90 s. Peter Rowe used this term in 1987 in his book ${ }^{(8)}$, in order to provide a practical problem-solving system to designers and city planners. And Richard Buchanan published an article ${ }^{(9)}$ explaining design thinking in 1995, and design thinking has since become more and more influential in dealing with thorny issues. 


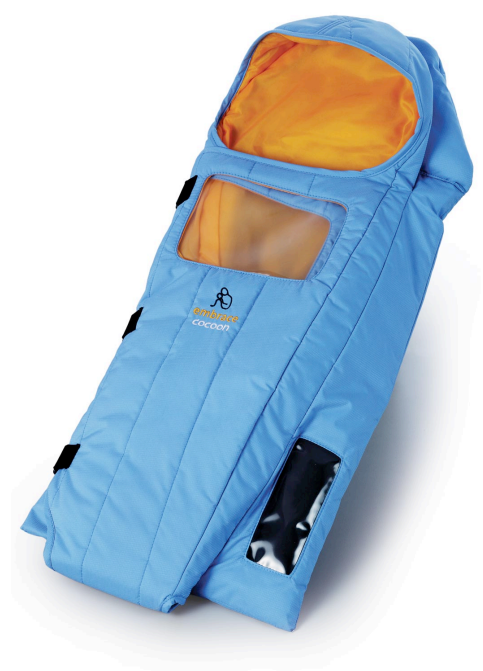

Fig. 1. The Embrace Warmer.

In 2004, Professor David Kelley from the Department of Mechanical Engineering at Stanford University founded the Institute of Design (D.School) ${ }^{(10)}$ at Stanford, and set up a design thinking course. Design thinking, now the most popular design method, is the result of integrating the traditional design method into social development. It's divided into five steps:

1) Empathizing: learning about the users for whom you are designing.

2) Defining: redefining and focusing on your question based on your insights gained from the empathizing step.

3) Ideating: brainstorming and coming up with creative solutions.

4) Prototyping: presenting one or more of your ideas to others.

5) Testing: returning to your original user group and testing your ideas for feedback.

With this design thinking method, D.School has successfully finished a lot of projects. The Embrace -warmer ${ }^{(11)}$ showed in Fig. 1 is one of its proud products. This product was specially designed for warming premature infants. In the poor areas of some developing countries, many preterm infants died in the hospital from the decline in body temperature- $98 \%$ of the premature mortality was caused by this reason. The students in D.School developed the product of Embrace Warmer based on design thinking, and thus helped many families. This design thinking is revolutionary, and it aims to balance the settlement of social problems and the commercial operations.

The design thinking in the modern times emphasizes ${ }^{(12)}$ : user research. The design thinking drives the innovation, which results from the user research and the technology.

\section{Case study: SPIED 2015}

\subsection{Brief of SPIED}

SPIED $^{(13)}$ was started in 2013 in Yamaguchi University, and this annual program has been held three times by now. SPIED is a two-week industrial innovation workshop, which involves students and teachers from different countries (China, Japan and South Korea), different universities and different disciplines. The first participants were engineering majors with knowledge about mechanical, electronic and information technology. From 2014, industrial design students were also included in this program. In this program, there are two classes, namely, the beginner class for the beginners and the advanced class for senior learners. The main purpose of this program is to "make things". Students gather in one place and share their knowledge and experiences through international team activities so as to learn how to create new ideas and products. Meanwhile, the teachers, who are also from different fields and universities, guide and inspire these students. These students, mostly majoring in engineering, the industrial design course needs to first put forward their own views. This case study is about the SPIED 2015 in Kunsan National University in South Korea.

\subsection{Setting of the industrial design course in the SPIED}

SPIED 2014, which was the second SPIED, began with a lecture introducing the industrial design course in the advanced class. Before the lecture, the students had started to work on the subject without the design thinking process and just for developing the technology. For example, a group of students developed a foul-smell removal system, as shown in Fig. 2. The principle for the project was as follows: firstly, using the smell sensor and camera to locate the foul smell; secondly, using the robot to automatically remove the foul smell. The students performed the project by following the procedure of problem discovery, technique research, system establishment and product development. The simulation was successful, and from the engineering perspective, the project was completed. However, this project was an application of the technology, and from the perspective of industrial designers, it was unfinished. For the same theme, an industrial designer will ask: 


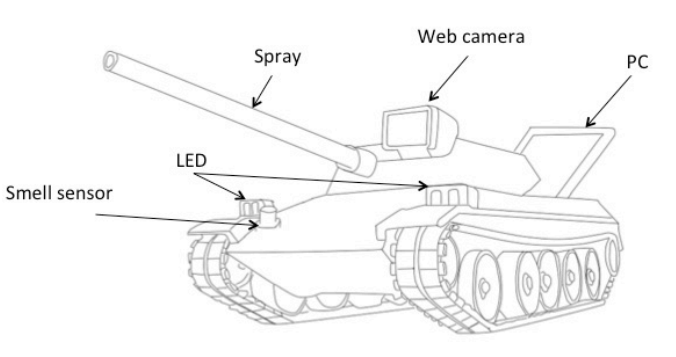

Fig. 2. The description of the smell sensor robot designed by the students (SPIED2014).

1) Who needs this product?

2) Why do they need this product?

3) Where will they use this product?

These user-centered questions will expand the concept of the product, and through investigating these questions, the students may find out more possible innovative points.

Figure 3 shows the different thinking modes of the engineering students and the design ones when handling the same project. The engineering students attached large importance to technological realization, and scarcely took into account commercialization, users and production feasibility-these factors should be given priority to. Actually, the concept of this smell sensor could have been expanded toward a lot of directions if the designers had combined their thinking with the research on the users during the design stage. They had missed a lot of innovation chances.

It was in the third SPIED program, namely, SPIED2015, that industrial design was included in the program as a thinking training course ${ }^{(14-16)}$. This time, in order to avoid the previous problem, the authors revealed the theme in the class. The authors tried to improve the design thinking of the students with the industrial design method. During the exercise, the students needed to find the possible innovative points. This time, the course was also taken in the advanced class.

Table 2 shows the procedure in the project. In the industrial design course, the exercise was mainly taken from Step 1 to Step 4. The content and purpose of the course are shown in Table 3:

1) Mind-map: diffuse the thinking from a word related to the theme.

2) Research work

2.1 Marketing: research on the demand of the market; competition against other products and brands; life style (based on the market); production plan.
Bad Smell Countermeasures System

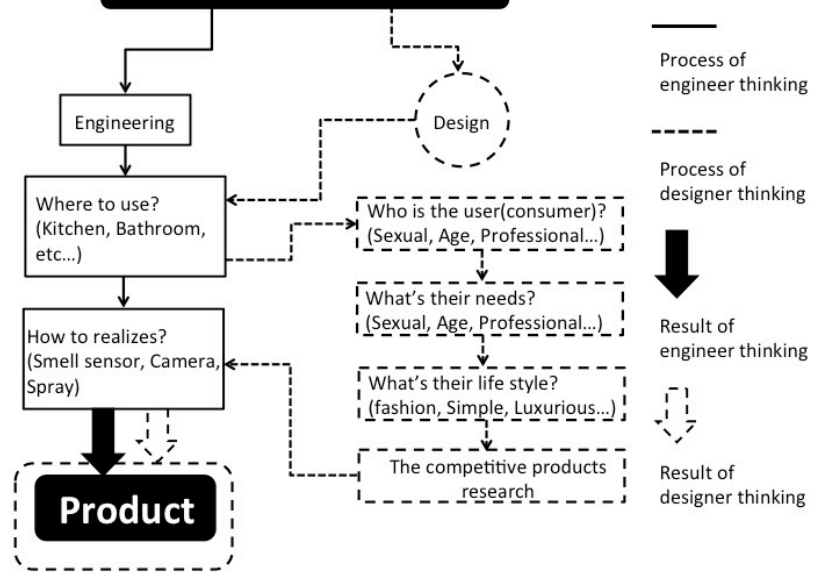

Fig. 3. Engineering and design thinking (SPIED 2014).

Table 3. The steps of the industrial design method (SPIED2015).

\begin{tabular}{ll}
\hline \multicolumn{1}{c}{ Step } & \multicolumn{1}{c}{ Purpose } \\
\hline 1. Mind-map & $\begin{array}{l}\text { Find the interesting points and diffuse } \\
\text { the thinking. }\end{array}$ \\
\hline 2. Research work & $\begin{array}{l}\text { Sift the ideas proposed in the mind map } \\
\text { and choose the final idea. }\end{array}$ \\
\hline 2.1.Marketing & $\begin{array}{l}\text { The market characteristic is decided by } \\
\text { the different cultures and policies. This } \\
\text { also influences the user property. }\end{array}$ \\
\hline 2.2. User & $\begin{array}{l}\text { Understand users, find their needs and } \\
\text { discover new user experience. }\end{array}$ \\
\hline 2.3. Technique & Study the realization of the product. \\
\hline $\begin{array}{l}\text { 2.4. Product } \\
\text { cycle }\end{array}$ & $\begin{array}{l}\text { It is a required response to the needs in } \\
\text { different design stages. }\end{array}$ \\
\hline 3. Design brief & $\begin{array}{l}\text { Clarify the project purpose, check the } \\
\text { progress and plan for the next stage. }\end{array}$ \\
\hline
\end{tabular}

2.2 User: user classification; persona creation (based on the user classification); action map (user behavior analysis)

2.3 Technique: summarize the previous research, and study related technique.

2.4 Product life cycle: consider the manufacturing, sales, use, and recycling of the product before the production.

3) Design brief: review the previous work and plan for the next stage after finishing the research and defining the idea.

After the class-exercise, a questionnaire survey was conducted to evaluate the effect of the industrial design course. 


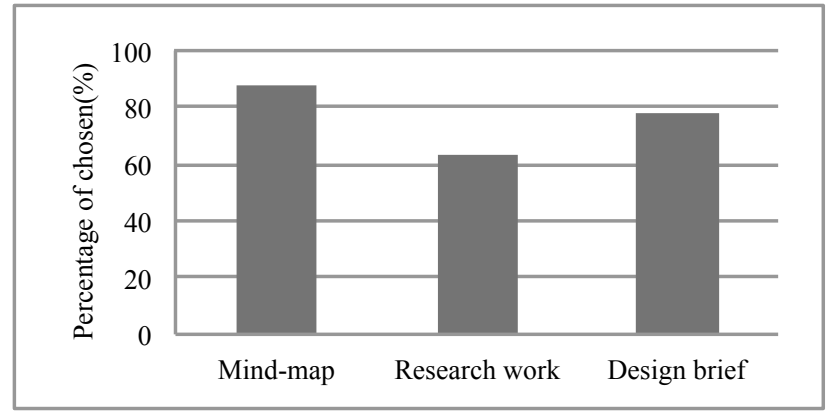

Fig. 4. The useful part of the industrial design method.

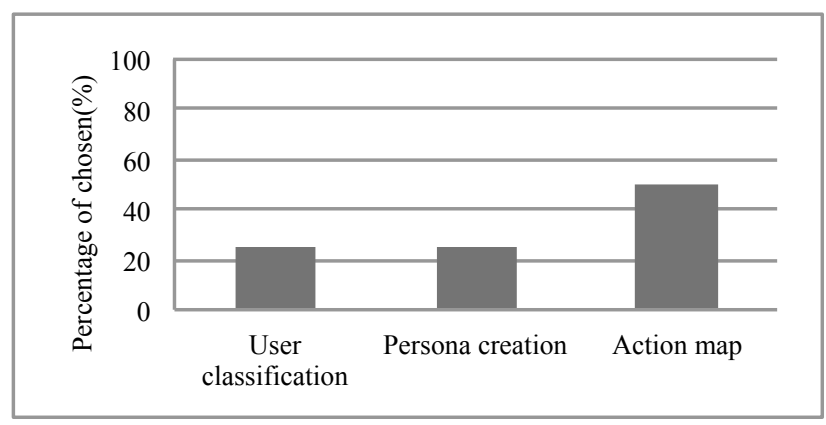

Fig. 5. The useful part of user research.

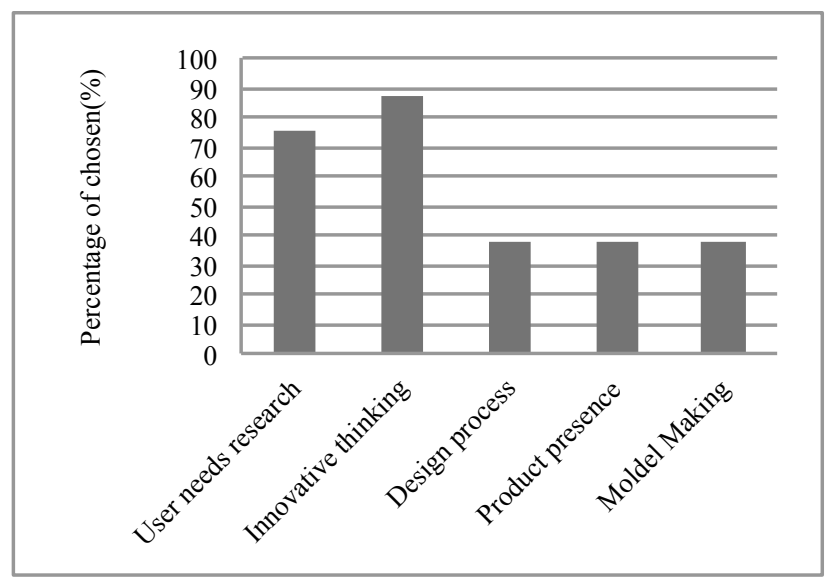

Fig. 6. The ratio of students with more interests in industrial design.

The results of the investigation into the useful part of the industrial design method (multiple choices) are shown in Fig. 4 below:

- $87.5 \%$ of the students chose the first step mind-map, probably because this was a familiar tool for them.

- $63.3 \%$ of them chose the second step, namely research work. This part, especially the user research part, was unfamiliar to the students, thus they didn't know how to carry out the research and accordingly find the possible innovative points. However, this was one of the most important parts in the process.

- $78 \%$ of them chose the third step, design brief. This part is superior to the second part. It was found that the students needed a break for reviewing the previous work and making the next-stage plan.

Figure 5 shows the result of an investigation into the useful part of user research. $50 \%$ of the students chose the action map. During the formation of the action map, which is based on the analysis of user behaviors, the designer should put themselves in the position of the users. During this process, a lot of problems could be revealed, and sometimes the solutions to these problems might be innovative points. In addition, both user classification and persona creation were the choice of $25 \%$ of the students.

\subsection{The idea of the course}

Firstly, for engineering students who hadn't studied the industrial design course before, design thinking was very unfamiliar. Considering that mind map had been used more commonly in engineering education, the authors first selected it as the starting point for the training.

Secondly, the students were guided to break through all the limitations and diffuse their thinking. By the time of the final step is their strong point, filter the ideas. There was a 'list' for selecting the suitable and finale idea. The 'list' was important, because it was the embodiment of the design methods. It was the research work in table 3. Through combining the design method with their familiar tools, the students could naturally understand and complete the procedure.

Finally, the design brief was written. Even for design students, the design brief was very important. According to the objective of the SPIED 2015, the authors created a list especially for the students:

1) Name of the product

2) In which market

3) Who is the user

4) Action map of the user

5) Concept of the product (sketching)

6) Product property: technique application/ material use/ color

7) Cost research

This was a summary of the stage. After the first two steps, the students would usually get confused about what the original purpose was, thus they needed a break for 
putting all the things in order and checking the previous steps. Then they were able to plan for the next progress.

\section{Conclusions}

The concept of innovation is very broad, though sometimes the innovation is a small part. Innovative thinking is just a thinking mode based on the market needs, user needs and technical requirements. Mind-map is the first step. It can start from any point of the view of the subject, and is used to open the mind. Then the students can select the possible ideas with the design methods and develop the ideas.

Sometimes students may quickly give up an idea just because the idea seems similar to other existing ones. In fact, creativity lies in the details. A product that is similar to others can also be considered innovative if it can bring better user experience. Educators should not only teach students methodology, but also check and guide their thinking to make them focus on the research work part.

As SPIED is an annual event, the method of training will continue to be refined and improved. According to the investigation into the SPIED 2015, 75\% of the students showed more interest in the user-need research and $87.5 \%$ of them wanted more trainings on innovative thinking (see Fig. 6). Most of the students claimed that the action map study provided them a new research way, and that industrial design course was useful both to their current study and to their future work. These inspiring feedbacks revealed the needs of the engineering students.

The result here is reached based on an experiment of combining the design thinking and engineering education. Furthermore, this paper is a summary of this stage and has its flaws. It is believed that design methods that better suit the students and satisfy the course requirements will be devised in the future. For the future task, we will try to summarize some standards to evaluate the creative activities. At the same time, it is hoped that this research can be helpful to engineering education.

\section{Acknowledgment}

This research was supported by the SPIED Committees.

\section{References}

(1) Alain Findeli: "Rethinking Design Education for the $21^{\text {st }}$ Century: Theoretical, Methodological and Ethical Discussion, Massachusetts Institute of Technology Design Issues, Vol. 17, No. 1, pp. 5-17, 2001

(2) Andersn, A.: "Implementation of engineering product design using international student teamwork-to comply with future needs ", European Journal of Engineering Education, Vol. 26, pp. 179-186, 2001

(3) Ian de Vera, Gavin Melles and Ajay Kapoor : "Product design engineering-global education trend in multidisciplinary training for creative product design", European Journal of Engineering Education, Vol. 35, No. 1, pp. 33-34, March 2010

(4) Cross, N.: "Engineering Design methods: strategies for product design", John Wiley \& Sons, Chichester (fourth), 2008

(5) Dym,C.IL., Agogino, A. M.,Eris,O., Fery, D.D. and Leifer, L.J.: "Engineering Design Thinking, Teaching, and Learning", Journal of Engineering Education, Vol.94, No.1, pp. 103-120, 2005

(6) ICSID: http://www.icsid.org/about/about.htm

(7) Bruno Munari: "Da cosa nasce cosa", Editori Laterza, 1981

(8) Peter G. Rowe: "Design thinking”, MIT Press, 1991

(9) Richard Buchanan and Victor Margolin: "Discovering Design: Explorations in Design Studies", University of Chicago Press, 1995

(10) D.School: http://dschool.stanford.edu/

(11) Embrace-warmer: http://embraceglobal.org/embrace-warmer/

(12) Tim Brown: "Design Thinking", Harvard Business Review, pp. 1-10, 2008

(13) SPIED: http://ire-asia.org/ire/spied/

(14) Cross,N.: "Designerly ways of knowing", Springer-Verlag Ltd, London, 2006

(15) Rivka Oxman: "Think-maps: teaching design thinking in design education", Design Studies, Vol. 25, No. 1, pp. 63-91, 2004

(16) Charles L. Owen: "Design thinking: Driving innovation", web article, http://bpminstitute.org/ 